\title{
Wax Deposition Modeling of Oil/Water Stratified Channel Flow
}

\author{
Zhenyu Huang, Michael Senra, Ravi Kapoor, and H. Scott Fogler \\ Dept. of Chemical Engineering, University of Michigan, 2300 Hayward St. Ann Arbor, MI 48109
}

DOI 10.1002/aic.12307

Published online June 22, 2010 in Wiley Online Library (wileyonlinelibrary.com).

\begin{abstract}
Wax deposition modeling becomes complicated when multiphase flow is involved. Empirical heat and mass transfer correlations are unreliable for multiphase deposition modeling and full scale computational fluid dynamics calculations require expensive computational intensity. In this work, numerical methods are used to study wax deposition in oil/water stratified flow through a channel. A unidirectional flow analysis is used to calculate the nonisothermal hydrodynamics and mass transfer. It was found that the change in the position of the oil/water interface throughout the channel must be taken into accounted for the mass balance to be valid. Unfortunately, this change has not been accounted for in all previous studies. In addition, the growth of the wax deposit as a function of time along with the effect of oil/water flow rate ratio is discussed. The presence of water significantly reduces the severity of wax deposition by altering the heat and mass transfer characteristics. $\odot 2010$ American Institute of Chemical Engineers AIChE J, 57: 841-851, 2011
\end{abstract}

Keywords: petroleum, transport, mass transfer, fluid mechanics

\section{Introduction}

\section{Basis of wax deposition}

Wax deposition in subsea oil pipelines is a significant economic problem in the petroleum industry. ${ }^{1-10}$ During transportation from the well head to shore, the crude oil travels along the ocean floor, which is about $4^{\circ} \mathrm{C}$. As drilling moves further offshore, the distance that the crude oil must travel increases and the temperature of the crude oil decreases. Subsequently, the wax in the crude oil can solidify as the temperature drops below its cloud point. The wax molecules can either deposit on the pipe wall or precipitate in the bulk liquid. The deposit of wax on the wall restricts the flow and can block the pipe, causing enormous losses in oil production. Each blockage can cause millions of dollars in downtime and remediation, as shown in Figure $1 .^{1}$

\footnotetext{
Correspondence concerning this article should be addressed to H. S. Fogler at sfogler@umich.edu.

(C) 2010 American Institute of Chemical Engineers
}

Predictive modeling of wax deposition has become an indispensable approach, not only to understand the fundamental physics of wax deposition during crude oil transportation in pipelines but also to design effective remediation strategies. However, most models are limited to single-phase flow, where reliable correlations for the hydrodynamics and heat/mass transfer are available. Wax deposition mechanisms have included molecular diffusion, shear dispersion, and Brownian diffusion. ${ }^{2,3}$ Among these mechanisms, molecular diffusion has been shown to be the dominant process in wax deposition and can be summarized in the following five major steps shown in Figure 2.,5

(1) Formation of an incipient deposit layer on the cold pipe wall surface.

(2) Convective mass flux of paraffin molecules from the bulk fluid toward the deposit (shown as A in Figure 2).

(3) Internal diffusive flux of paraffin molecules in the deposit layer (B). The difference between the convective mass flux and the diffusive mass flux results in the growth of the deposit thickness (C). 


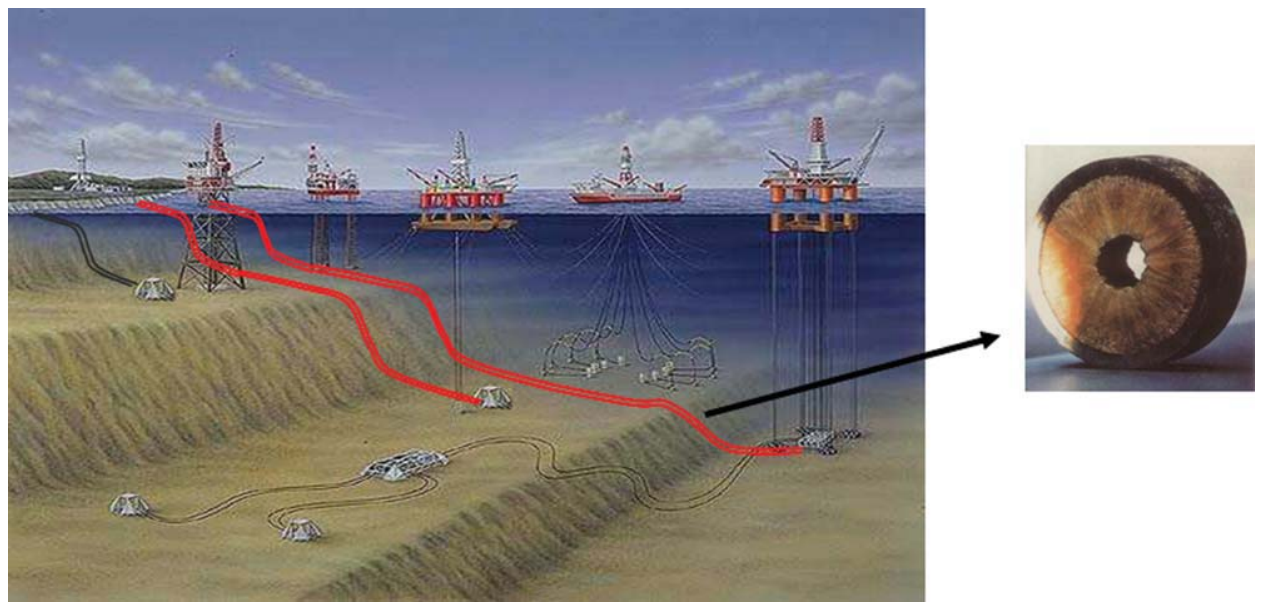

Figure 1. Petroleum transportation in subsea pipelines. ${ }^{1}$

[Color figure can be viewed in the online issue, which is available at wileyonlinelibrary.com.]

(4) Precipitation of paraffin molecules inside the deposit, which leads to the increase of solid wax fraction of the deposit.

(5) Counter-diffusion of dewaxed oil out of the deposit.

A number of mathematical models have used molecular diffusion to predict wax deposition in oil pipelines. Early models attempted to predict the growth of the deposit thickness using the radial convective mass flux of the wax molecules. $^{2-4,6,7}$ Unfortunately, these early models all assumed the wax content inside the gel to be constant, and it is now known that the wax fraction in the deposit increases as the deposit thickens. ${ }^{8,9}$ This phenomenon is called aging and causes an increase in the thermal conductivity of the deposit layer and a decrease in the molecular diffusivity of wax in the deposit. These issues were not accounted for in the models referenced above.

Singh and Fogler developed the first model to successfully study the effects of aging in wax deposition, which precisely predicted not only the growth of thickness but also the increase of wax fraction in the deposit. ${ }^{9}$ The wax fraction is an indicator of gel strength, an important parameter for designing remediation methods such as pigging. However, the heat and mass transfer correlations used in this model can over-predict the deposition rate for turbulent flow conditions because they assume that the temperature and concentration fields are independent, a situation only valid in laminar flow. This laminar flow model correctly neglects the precipitation of wax molecules in the oil phase. However, wax precipitation in the oil is an important issue in turbulent flow where the cooling rate of the oil is relatively slow. A refinement of this model used the "solubility method" in the boundary layer, which assumed that precipitation depends solely on the solubility of wax in the oil. ${ }^{10}$ This solubility approach can under predict the thickness of the deposit because it does not account for the supersaturated wax molecules that do not have sufficient time to precipitate during their residence in the pipe. The solubility approach represents a lower bound on the deposit thickness, whereas the use of independent heat and mass transfer correlations represents the upper bound of wax buildup. The approach developed by Lee ${ }^{1}$ accounted for the precipitation kinetics in the boundary layer, leading to predictions between those by
Singh's method of independent heat and mass transfer ${ }^{9}$ and Venkatesan's solubility method. ${ }^{10}$

\section{Multiphase flow regimes}

As offshore drilling becomes increasingly important in the petroleum industry, water is commonly seen in the subsea pipelines. ${ }^{11,12}$ In wax deposition modeling, knowledge of the hydrodynamics and heat/mass transfer are the major challenges in two-phase flow because a variety of flow patterns can exist. Each pattern has its own unique transport phenomena. A typical flow map of a liquid/liquid two-phase flow is shown in Figure 3. ${ }^{13}$

Wax deposition in oil-centered annular flow would rarely occur because oil is not in contact with the pipe. Studies of intermittent (slug) flow are highly empirical because of the instability of the slugs and the difficulty to identify an averaged slug length and slug frequency. ${ }^{11}$ For dispersed flow, the single-phase wax deposition mechanism may be difficult to modify and apply because of emulsions and phase inversion. Oil/water stratified flow will be examined in this research because of its frequent occurrence in pipeline transportation and because of its tractability. ${ }^{12}$ Additionally, the oil phase has a relatively large contact area with the pipe wall, allowing deposition to occur.

Although heat and mass transfer correlations are well established for single-phase models, they cannot be directly applied to multiphase models. The first attempt to study

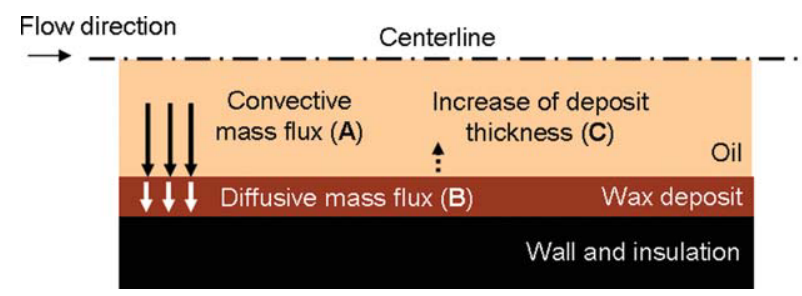

Figure 2. Schematic of wax deposition in subsea pipelines.

[Color figure can be viewed in the online issue, which is available at wileyonlinelibrary.com.]

April 2011 Vol. 57, No. 4 AIChE Journal 


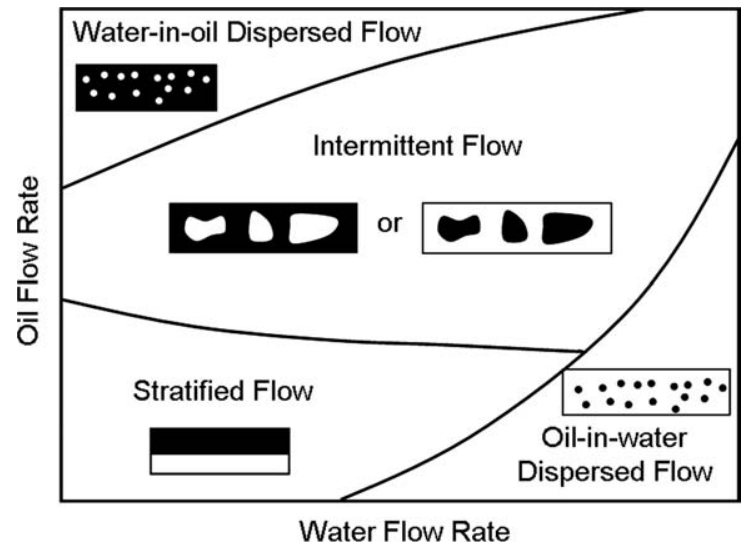

Figure 3. A flow map of oil/water two-phase flow by Shi et al. ${ }^{13}$

The dark part in the flow represents oil, whereas the light part represents water.

multiphase wax deposition was for gas/oil two-phase flow. ${ }^{14}$ However, using the heat transfer correlations provided by Kim et al., not one of the 20 gas/liquid correlations used in this study was able to predict the experimental deposit thickness. ${ }^{15}$ In an attempt to remedy this problem, several material properties, such as the thermal conductivity of oil and the diffusivity of wax in oil, were "tuned" unrealistically by factors as much as 5 without any convincing physical explanations and perhaps most importantly, these results cannot be applied to other experiments or systems.

Recent advances in computational fluid dynamics (CFD) have made it possible to calculate multiphase transport phenomena without the use of correlations. However, very little research on multiphase wax deposition using CFD has been undertaken because of the computational intensity required. To model multiphase wax deposition, nonisothermal hydrodynamics and transport phenomena need to be calculated for three phases (oil, water, and deposit). As the deposit grows on the pipe wall, the oil/water interface and oil/deposit interface are two moving boundaries that need to be updated at each time step. For oil/water stratified flow, the complexity in geometry provides great difficulty in $3 \mathrm{D}$ modeling, especially for field-scale predictions. Consequently, to gain a qualitative understanding and insight of wax deposition in multiphase flow, a 2D model is established using a unidirectional flow assumption to study wax deposition in oil/water stratified flow. The decrease in dimensions and the unidirectional flow assumption significantly reduce the computational intensity and provide insight on how water influences wax deposition in oil/water stratified flow.

\section{Mathematical analysis and model development}

Hydrodynamics in Isothermal Flows. Numerous studies on the hydrodynamics of stratified flow have been carried out, most focusing on calculating the velocity distribution, the stress at the wall/interface, and the predicting phase volume fraction under isothermal conditions. ${ }^{12,16} \mathrm{Yu}$ and Sparrow developed an analytical velocity profile of stratified flow of two immiscible fluids by reducing the Navier-Stokes equation to a Green's function assuming a horizontal inter-

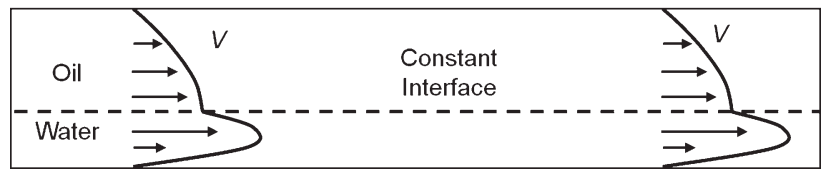

Figure 4. Schematic of isothermal velocity profile of oil/water stratified flow.

face. ${ }^{12} \mathrm{Ng}$ et al. studied the velocity profile under a circular interface shape in a pipe using a boundary-element method. ${ }^{16}$ Because these studies are all based on isothermal conditions, constant pressure-drop and interface position (CPIP) are maintained throughout the pipe. An example of the velocity profile of oil/water stratified flow in the subsea pipelines under isothermal conditions is shown in Figure 4.

This isothermal assumption might be valid in deposition modeling of small-scale flow loop experiments where the bulk temperature does not decrease enough to cause a substantial change of the interface position. However, due to the significant decrease in fluid temperature along the subsea pipelines and in model channel flows, the hydrodynamics must be reexamined for nonisothermal conditions.

Hydrodynamics in Nonisothermal Flows. As the temperature of the fluids decreases along the channel, the viscosities of both water and oil increase. This increase in the viscosities leads to an increase in the pressure-drop along the channel. More importantly the kinematic viscosity of oil, also known as its momentum diffusivity, increases more rapidly than that of water, leading to a greater decrease of momentum in oil than that of water. As a result, the oil phase flows with smaller velocity and larger cross sectional area. Contrarily, the water phase flows with larger velocity and smaller cross sectional area. A schematic of this change in hydrodynamics is shown in Figure 5. If one were to directly input the constant value of the pressure-drop and the heights of both phases to calculate the velocity profile as in isothermal conditions, the flow rate of both oil and water is not conserved, and the mass balance is violated.

To mathematically account for the change in hydrodynamics in nonisothermal flow conditions, the temperature-dependence of the viscosity of oil and water must be evaluated. One may think of solving the momentum balance equations in three dimensions to account for the secondary flows and the change of hydrodynamics along the pipe. However, such an approach is too computationally intensive to be practical for deposition modeling in field scale operations where the hydrodynamics needs to be updated continuously during the time of deposition. Fortunately, one notes the gradual

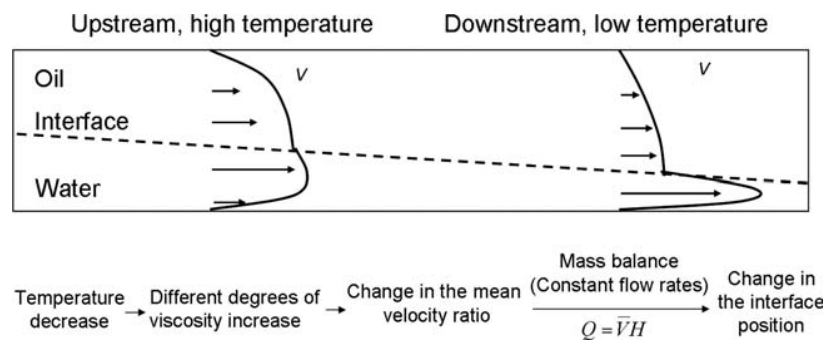

Figure 5. Schematic of nonisothermal velocity profile of oil/water stratified flow. 


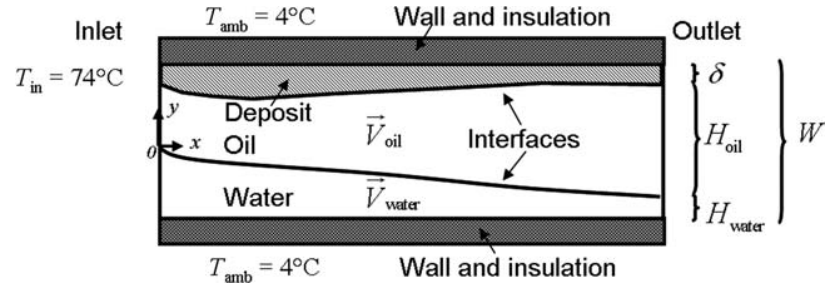

Figure 6. Schematic of hydrodynamics of oil/water stratified flow.

decrease in the fluid temperatures due to pipeline insulation results in a smooth change of hydrodynamics along the pipe. This fact enables the application of a unidirectional-flow simplification at every axial position to calculate the velocity profile without intensive iteration. With this simplification, a deposition model is developed for nonisothermal laminar flows of oil and water between two parallel plates shown in Figure 6. In this case, wax deposition occurs only at the upper wall when water is present.

For the oil and water flow shown schematically in Figure 6, the corresponding velocity profile can be found from the analytical solution of the 2D Navier-Stokes equations shown in Eqs. 1-3.

$$
\begin{array}{r}
V_{\text {oil }}(y)=\left\{u_{\text {water }}\left[1-\frac{u_{\text {oil }}}{u_{\text {water }}}\left(\frac{y}{H_{\text {oil }}}\right)^{2}\right]+\left(\frac{u_{\text {oil }}-u_{\text {water }}}{1+K}\right)\right. \\
\left.\times\left[1+K\left(\frac{y}{H_{\text {oil }}}\right)\right]\right\} \frac{d P}{d x} \\
V_{\text {water }}(y)=\left\{u_{\text {water }}\left[1-\left(\frac{y}{H_{\text {water }}}\right)^{2}\right]+\left(\frac{u_{\text {oil }}-u_{\text {water }}}{1+K}\right)\right. \\
\left.\times\left[1+\left(\frac{y}{H_{\text {water }}}\right)\right]\right\} \frac{d P}{d x} \\
H_{\text {oil }}+H_{\text {water }}+\delta=W
\end{array}
$$

with

$$
K=\frac{\mu_{\text {water }}}{\mu_{\text {oil }}} \frac{H_{\text {oil }}}{H_{\text {water }}}, \quad u_{\text {oil }}=-\frac{H_{\text {oil }}^{2}}{2 \mu_{\text {oil }}}, \quad u_{\text {water }}=-\frac{H_{\text {water }}^{2}}{2 \mu_{\text {water }}}
$$

From Eqs. 1-4, it can be seen that the velocity profile of water/oil stratified channel flow is dependent on the viscosity of oil and water, $\mu_{\mathrm{o}}$ and $\mu_{\mathrm{w}}$, the height of both phases, $H_{\mathrm{o}}$ and $H_{\mathrm{w}}$, and the pressure-drop, $\frac{d p}{d x}$. The viscosities of both phases are determined by the bulk temperatures at a particular axial location:

$$
\mu_{\mathrm{oil}}=\mu_{\mathrm{oil}}\left(T_{\mathrm{b}, \mathrm{oil}}\right) \text {, and } \mu_{\mathrm{water}}=\mu_{\mathrm{water}}\left(T_{\mathrm{b}, \text { water }}\right),
$$

Because of the insulation on the outer wall, the effect of the difference in the viscosity on the velocity profile caused by the change of temperature in the vertical direction is neglected. This assumption is verified by comparing the velocity profiles of oil and water in this model with those obtained by a commercial CFD software FLUENT, under the same conditions. In the calculations using FLUENT, the radial dependence of viscosity on temperature is considered. The velocity profiles of these two approaches indicate a negligible difference under common pipeline flow conditions.
To maintain the conservation of the mass flow rate, the pressure-drop, $\frac{d p}{d x}$, and the height of oil and water, $H_{\mathrm{o}}$, and $H_{\mathrm{w}}$ along the channel must be calculated instead of being specified a priori. This calculation consists of three steps:

(1) The volumetric flow rate of each phase per unit depth of the channel is obtained by integrating the velocities of both oil and water (Eqs. 1 and 2) over the height of each phase in the channel.

$$
\begin{gathered}
Q_{\text {oil }}=\left[u_{\text {water }}-\frac{u_{\text {oil }}}{3}+\frac{u_{\text {oil }}-u_{\text {water }}}{1+K}\left(1+\frac{K}{2}\right)\right] H_{\text {oil }} \frac{d P}{d x} \\
Q_{\text {water }}=\left[\frac{2}{3} u_{\text {water }}+\frac{u_{\text {oil }}-u_{\text {water }}}{2(1+K)}\right] H_{\text {water }} \frac{d P}{d x}
\end{gathered}
$$

To determine the height of the oil-water interface, the ratio of Eqs. 6 and 7 is used to cancel the pressure-drop term to obtain the height ratio as a function of the flow rate ratio and the viscosity ratio of the two phases:

$$
\frac{H_{\mathrm{ow}}^{4}}{\mu_{\mathrm{ow}}^{2}}+4 \frac{H_{\mathrm{ow}}^{3}}{\mu_{\mathrm{ow}}}+3 \frac{\left(1-Q_{\mathrm{ow}}\right)}{\mu_{\mathrm{ow}}} H_{\mathrm{ow}}^{2}-4 \frac{Q_{\mathrm{ow}}}{\mu_{\mathrm{ow}}} H_{\mathrm{ow}}-Q_{\mathrm{ow}}=0
$$

where

$$
Q_{\mathrm{ow}}=\frac{Q_{\mathrm{oil}}}{Q_{\text {water }}}, \quad H_{\mathrm{ow}}=\frac{H_{\mathrm{oil}}}{H_{\text {water }}}, \quad \mu_{\mathrm{ow}}=\frac{\mu_{\mathrm{oil}}}{\mu_{\text {water }}}
$$

At a particular axial location with known viscosities and flow rate ratios, the heights of both phases, $H_{\mathrm{o}}$ and $H_{\mathrm{w}}$ can be obtained by solving Eqs. 8 and 3 simultaneously.

(2) The pressure-drop, $\frac{d p}{d x}$, can be solved using either Eq. 6 or 7 .

(3) The velocity profiles in Eqs. 1 and 2 can be readily determined by knowing the viscosity ratio, the height of each phase and the pressure-drop as previously calculated. The overall algorithm for the calculation is shown in Figure 7.

One should note that according to Eq. 8, the increase in the ratio of the viscosities results in the increase in the ratio of the heights of the two phases. In fact, this trend can be found in previous experiments and theoretical studies of stratified flows in circular pipes, where a higher ratio of the viscosities of the two phases leads to a higher ratio of the

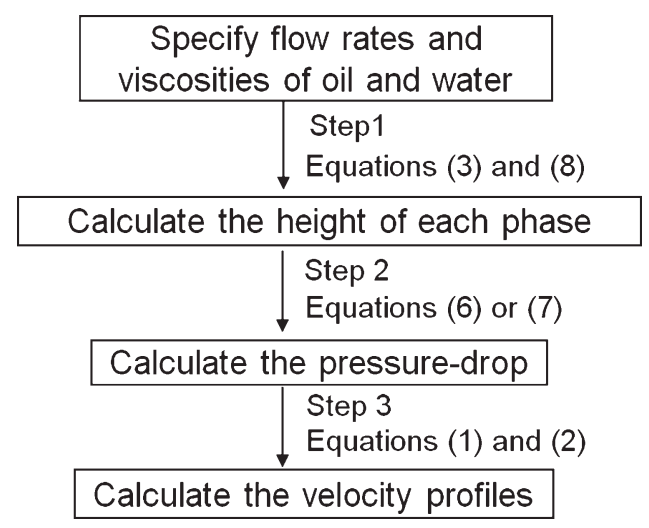

Figure 7. The algorithm to calculate the velocity profile for nonisothermal conditions.

April 2011 Vol. 57, No. 4

AIChE Journal 


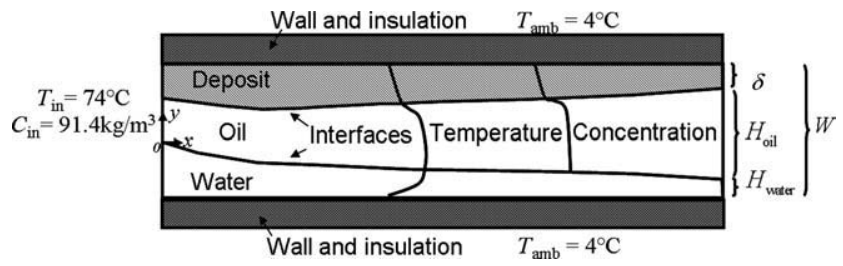

Figure 8. Schematic of wax deposition in oil/water laminar stratified channel flow.

corresponding cross sectional areas when their flow rates are constant. $^{16,17}$

\section{Heat and mass transfer}

The temperature and concentration profiles are shown schematically in Figure 8. The temperature profile is calculated using the energy balance, Eq. 10, assuming a quasisteady state in which axial conduction is neglected. ${ }^{18}$

$$
\rho C_{\mathrm{p}} V_{x}(y) \frac{\partial T}{\partial x}=\frac{\partial}{\partial y}\left(k \frac{\partial T}{\partial y}\right)
$$

The thermal boundary condition assumes a constant inlet temperature and a continuous heat fluxes at the walls. The external heat transfer coefficient is constant accounting for the thermal resistance of the insulation material and the surrounding sea:

$$
\left\{\begin{array}{l}
\text { when } y=-H_{\mathrm{water}}, \text { then }-k_{\mathrm{water}} \frac{\partial T}{\partial y}=h\left(T_{\mathrm{wall}}-T_{\mathrm{amb}}\right) \\
\text { when } y=H_{\mathrm{oil}}, \text { then }-k_{\mathrm{dep}} \frac{\partial T}{\partial y}=h\left(T_{\mathrm{amb}}-T_{\mathrm{wall}}\right) \\
\text { when } x=0, \text { then } T=T_{\mathrm{in}}
\end{array}\right.
$$

The concentration profile is calculated using the mass balance, Eq. 12, for mass transfer in which axial diffusion is neglected. ${ }^{18}$

$$
V_{x}(y) \frac{\partial C}{\partial x}=\frac{\partial}{\partial y}\left(D_{\text {wo }} \frac{\partial C}{\partial y}\right)
$$

The precipitation of wax molecules in the bulk oil is neglected, which is valid for laminar flow. ${ }^{9}$ The impermeable boundary condition at the oil/water interface is imposed, assuming that wax molecules do not dissolve in the water phase. For the deposit phase, it is assumed that the wax concentration obeys liquid/solid equilibrium, shown in Eq. 13. A simple implicit scheme is used to solve the above equations using FORTRAN. ${ }^{19}$

$$
\left\{\begin{array}{l}
\text { when } y<0 \text {, then } C=0 \\
\text { when } y=0 \text {, then } \frac{\partial C}{\partial y}=0 \\
\text { when } H_{\text {oil }}<y<\left(H_{\text {oil }}+\delta\right), \text { then } C=f_{\text {solubility }}(T) \\
\text { when } x=0, \text { then } C=C_{\text {in }}
\end{array}\right.
$$

\section{Deposition mechanism}

Because molecular diffusion is the primary deposition mechanism, we know that the convective wax flux from the bulk crude to the wax-oil interface, $J_{\text {interface,conv }}$ is equal to the rate of increase in the deposit thickness plus the flux into

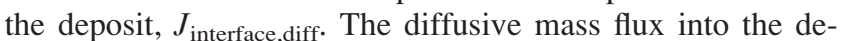
posit interface, $J_{\text {interface,diff, }}$ contributes to the increase of the wax fraction in the deposit as a function of time, shown in Eqs. 14 and $15 .^{9}$

$$
\delta \rho_{\mathrm{gel}} \frac{d \bar{F}_{\mathrm{w}}(t)}{d t}=J_{\text {interface, diff }}=-\left.D_{\text {eff }} \frac{\partial C}{\partial y}\right|_{\text {interface, gel }}
$$

$$
\begin{aligned}
\bar{F}_{\mathrm{w}}(t) \rho_{\mathrm{gel}} \frac{d \delta}{d t}=J_{\text {interface,conv }}-J_{\text {interface,diff }} \\
=\left(-\left.D_{\mathrm{wo}} \frac{\partial C}{\partial y}\right|_{\text {interface,fluid }}\right)-\left(-\left.D_{\text {eff }} \frac{\partial C}{\partial y}\right|_{\text {interface,gel }}\right)
\end{aligned}
$$

\section{Simulation conditions}

Taking similar length scales to field scale subsea pipelines, the width between the plates is $0.3 \mathrm{~m}$. The overall heat transfer coefficient, including the insulation material and the sea, is $1 \mathrm{~W} /\left(\mathrm{m}^{2} / \mathrm{K}\right)$. The inlet temperature is $74^{\circ} \mathrm{C}$ and the surrounding ambient temperature is $4^{\circ} \mathrm{C}$, which are typical conditions seen in the subsea pipelines. The properties of the oil are presented in Table 1 and Figure 9. The diffusivity of wax molecules in oil is calculated by the correlation given by Hayduk and Minhas. ${ }^{20}$ The effective diffusivity is obtained by the correlation given by Cussler et al. ${ }^{21}$

Six simulations were carried out in this study. The oil and water flow rates for these six simulations are given per unit depth of the channel along with the Reynolds number and shown in Table 2.

Simulation 1 is carried out to predict wax deposition in single-phase oil flow and is used as the base case. Simulations 2 and 3 are carried out to compare the change in hydrodynamics of oil/water flow between using two different approaches. Incorporating the change in the pressure-drop and in the oil/water interface position in the calculations, simulations 3-6 are carried out to study the effect of water flow rate on wax deposition. To better describe the simulation results in further discussions, the water/oil and the oil/ deposit interface positions are dedimensionalized by dividing by the width of the channel. Additionally, the pressure-drop, velocities, and flow rates are dedimensionalized by dividing by the corresponding values at the inlet.

\section{Results and Discussion}

\section{Deposition results for single-phase oil flow}

The development of wax thickness is studied for different water/oil flow rate ratios. As a base case, the development of the wax deposit for single-phase oil flow (Simulation 1 in

Table 1. The Properties of the Oil Analyzed in This Study

\begin{tabular}{lc}
\hline Cloud point, $T_{\mathrm{c}}$ & $40^{\circ} \mathrm{C}$ \\
Specific heat, $C_{\mathrm{p}}$ & $2500 \mathrm{~J} / \mathrm{K} / \mathrm{kg}$ \\
Density of oil, $\rho_{\text {oil }}$ & $840 \mathrm{~kg} / \mathrm{m}^{3}$ \\
Density of wax, $\rho_{\text {wax }}$ & $840 \mathrm{~kg} / \mathrm{m}^{3}$ \\
Thermal conductivity, $k$ & $0.14 \mathrm{~W} / \mathrm{m} / \mathrm{K}$ \\
\hline
\end{tabular}


(a) Solubility of Wax in Oil

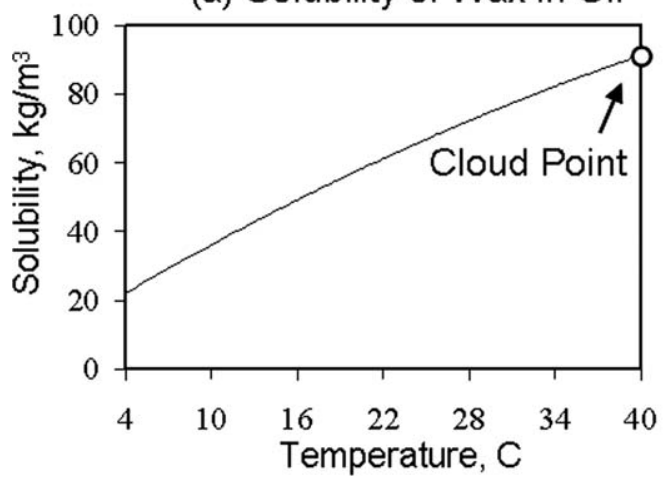

(b) Viscosity of oil

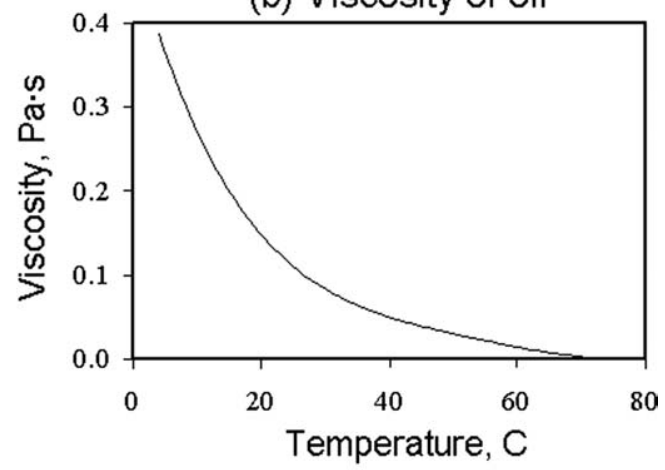

Figure 9. (a) Solubility of the wax in the oil and (b) viscosity of the oil in this study.

Table 2) is shown in Figure 10. A maximum in the deposit thickness near the inlet of the channel is observed.

This maximum can be explained by examining the concentration of wax at the bulk, $C_{\mathrm{B}}$, and the concentration of wax at the oil-deposit interface $C_{\text {Interface }}$. The bulk concentration of soluble wax is calculated by taking a velocityweighted average of the axial ( $x$-direction) concentration profile throughout the oil phase. ${ }^{18}$

$$
C_{\mathrm{B}}(x)=\frac{\int_{0}^{H_{\text {oil }}} C(x, y) V_{\text {oil }}(x, y) d y}{\int_{0}^{H_{\text {oil }}} V_{\text {oil }}(x, y) d y}
$$

The difference between $C_{\mathrm{B}}$ and $C_{\text {Interface, }}$ i.e., $\left(C_{\mathrm{B}}-C_{\text {Interface }}\right)$, represents the concentration driving force for wax deposition and is shown along with the concentration profiles throughout the channel in Figure 11.

It is seen that the concentration of wax at the wall decreases drastically near the inlet. This decrease can be explained by the significant amount of precipitation of liquid wax on the upper wall near the inlet because of the decrease in the upper-wall temperature.

The decrease in the concentration of wax at the upper wall results in an increase of the mass driving force for deposition. In other words, a significant amount of wax is transported onto the interface to deposit, which leads to an increase of the growth rate of the deposit thickness along the channel. One notes the large driving force near the channel entrance gives rise to a large increase in the deposit thickness near the inlet, shown in Figure 10. However, as the oil flows further down the channel, the depletion of soluble wax from the flowing oil due to precipitation becomes so significant that the driving force for wax deposition decreases, thereby reducing the growth rate of the deposit.

\section{Deposition results for two-phase flow}

The Change of Hydrodynamics in Nonisothermal Flow. In the hydrodynamics for single-phase deposition modeling, the change in viscosity with temperature (and, hence, axial distance) is seen to only affect the mass transfer by affecting the diffusivity of wax in oil. ${ }^{1,9,10}$ However, in oil/water stratified flow, the change in viscosity with distance can drastically alter the hydrodynamics. Simulations 2 and 3 are carried out to compare the change of hydrodynamics of isothermal and nonisothermal conditions on wax deposition. The pressure-drop, flow rates, velocities, and temperatures at the inlet are the same in both simulations. However, Simulation 2 uses a velocity profile throughout the channel obtained from CPIP model. Although the CPIP model is correct for isothermal operations, it is not correct for nonisothermal flows because it violates the conservation of mass. Simulation 3 uses the correct velocity profile with variable pressure-drop and interface position (VPIP) based on the conservation of mass. Under nonisothermal flow conditions, the bulk temperature of each phase at a certain axial location is calculated by taking a vertical velocity-weighted average of temperature throughout each phase. ${ }^{18}$

Table 2. The Flow Rates and Inlet Reynolds Numbers of Oil and Water in the Simulations

\begin{tabular}{|c|c|c|c|c|c|c|}
\hline $\begin{array}{l}\text { Simulation } \\
\text { Number }\end{array}$ & $\begin{array}{c}\text { Flow Rate Ratio } \\
\text { Water/Oil }\end{array}$ & $\begin{array}{l}\text { Oil Flow Rate Per } \\
\text { Unit Depth }\left(\mathrm{m}^{2} / \mathrm{s}\right)\end{array}$ & Oil Inlet $R e$ & $\begin{array}{c}\text { Water Flow Rate Per } \\
\text { Unit Depth }\left(\mathrm{m}^{2} / \mathrm{s}\right)\end{array}$ & Water Inlet $R e$ & $\begin{array}{c}\text { Pressure-Drop } \\
\text { and Interface Position }\end{array}$ \\
\hline 1 & 0 & $10^{-4}$ & 82 & 0 & 0 & NA* \\
\hline 2 & 8 & $10^{-4}$ (Inlet) & 82 & $8 \times 10^{-4}$ & 2054 & Constant \\
\hline 3 & 8 & $10^{-4}$ & 82 & $8 \times 10^{-4}$ & 2054 & Varied \\
\hline 4 & 0.5 & $10^{-4}$ & 82 & $5 \times 10^{-5}$ & 128 & Varied \\
\hline 5 & 1 & $10^{-4}$ & 82 & $1 \times 10^{-4}$ & 257 & Varied \\
\hline 6 & 4 & $10^{-4}$ & 82 & $2 \times 10^{-4}$ & 1027 & Varied \\
\hline
\end{tabular}

*In single-phase oil flow, only the pressure-drop changes due to the change of viscosity along the pipe. 
(a) 90 days

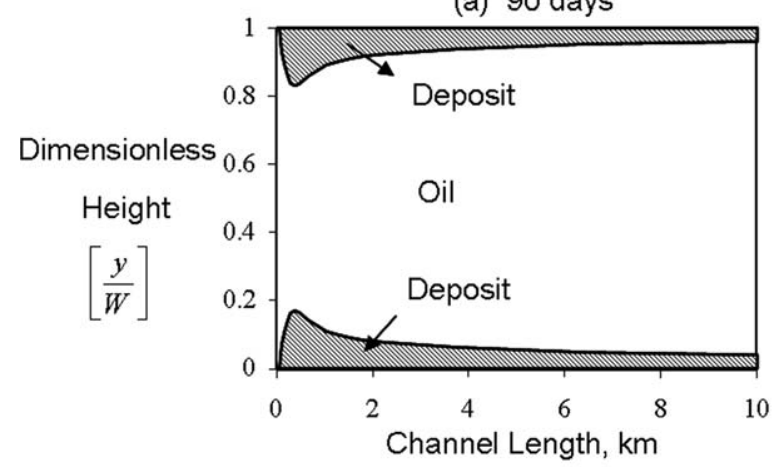

(b) 180 days

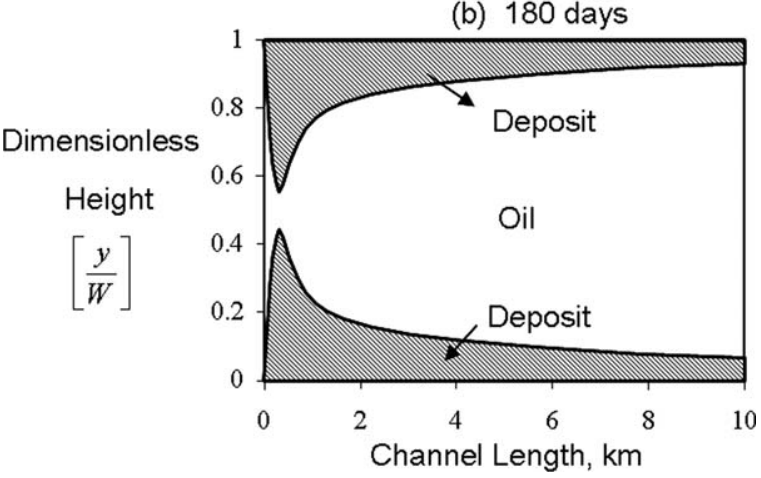

Figure 10. The growth of the deposit thickness in single-phase flow (Simulation 1).

$$
\begin{gathered}
T_{\mathrm{B}, \text { oil }}(x)=\frac{\int_{0}^{H_{\text {oil }}} T(x, y) V_{\text {oil }}(x, y) d y}{\int_{0}^{H_{\text {oil }}} V_{\text {oil }}(x, y) d y}, \\
T_{\mathrm{B}, \text { water }}(x)=\frac{\int_{H_{\text {water }}}^{0} T(x, y) V_{\text {water }}(x, y) d y}{\int_{-H_{\text {water }}}^{0} V_{\text {water }}(x, y) d y}
\end{gathered}
$$

Table 3 shows the bulk temperatures of oil and water and the corresponding viscosities of both phase at the inlet and outlet initially (i.e., $t=0$ ) when no deposition has yet occurred.

It is seen that despite the difference in the outlet bulk temperatures and viscosities between the CPIP and VPIP models, both approaches predict a significant decrease in the outlet bulk temperatures and increase in the outlet viscosities of oil and water compared with the inlet. For the correct approach, i.e., VPIP, this decrease in the viscosities causes an increase in the pressure-drop shown in Figure 12. (a) Concentration at the bulk and wall

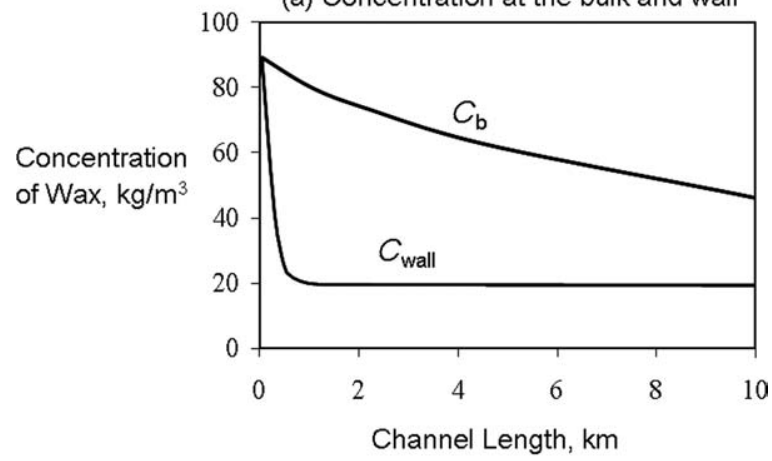

(b) Driving force for mass transfer

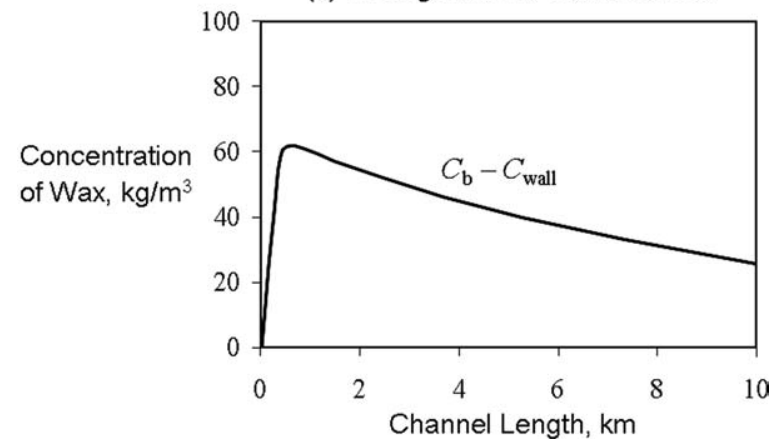

Figure 11. (a) The concentration profile and (b) the driving force for deposition initially $(t=0)$ when no wax deposit is formed for singlephase flow (Simulation 1).

One notes that in the VPIP model, due to the drastic increase in the viscosities of both oil and water, the pressure-drop increases rapidly after the inlet. This increase reaches more than 30 times at the outlet. In the CPIP model, the pressure-drop remains constant throughout the channel. More importantly, it can be seen from Table 3 that the viscosity of oil increases more significantly than that of water at the outlet. With the VPIP model, this increase in the ratio of viscosity of oil/water leads to a decrease in the velocity of oil as well as an increase in the velocity of water. To maintain the constant flow rate of each phase, the oil must flow with an increasing cross sectional area, whereas the water flows with a decreasing cross sectional area. The change in the oil/water interface for the VPIP model is shown in Figure 13. It is seen that the height of the oil phase has increased $\sim 200 \%$ at the outlet.

Contrarily, in the CPIP model, both the pressure-drop and the position of the oil/water interface remain constant shown in Figures 12 and 13. This CPIP constraint leads to a significant decrease in the flow rates of both oil and water, shown

Table 3. A Comparison of Bulk Temperatures and Viscosities of Oil and Water at the Inlet and Outlet for CPIP and VPIP Initially $(t=0)$ When No Wax Deposit is Formed

\begin{tabular}{ccccccccc}
\hline & $T_{\text {in,oil }}\left({ }^{\circ} \mathrm{C}\right)$ & $T_{\text {out,oil }}\left({ }^{\circ} \mathrm{C}\right)$ & $T_{\text {in,water }}\left({ }^{\circ} \mathrm{C}\right)$ & $T_{\text {out,water }}\left({ }^{\circ} \mathrm{C}\right)$ & $\mu_{\text {in,oil }}(\mathrm{cp})$ & $\mu_{\text {out,oil }}(\mathrm{cp})$ & $\mu_{\text {in,water }}(\mathrm{cp})$ & $\mu_{\text {out,water }}(\mathrm{cp})$ \\
\hline CPIP & 74.00 & 4.00 & 74.00 & 4.00 & 1.03 & 386.98 & 0.39 & 1.58 \\
VPIP & 74.00 & 5.64 & 74.00 & 6.03 & 1.03 & 351.18 & 0.39 & 1.49 \\
\hline
\end{tabular}




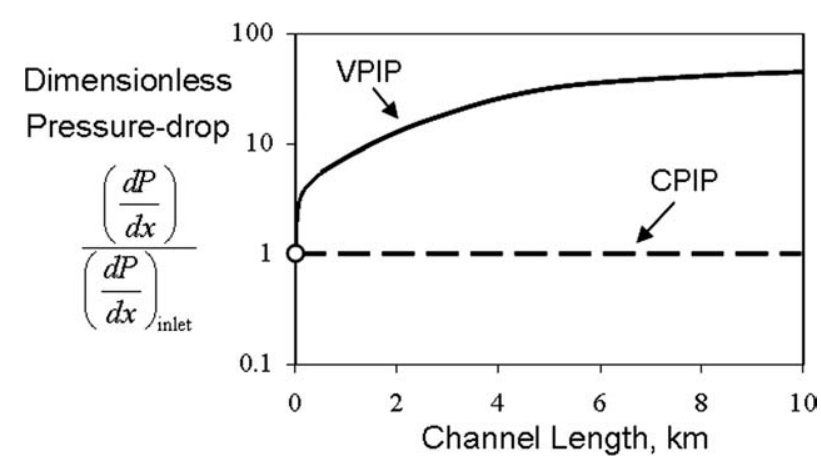

Figure 12. The pressure-drop throughout in the channel in the VPIP model initially when no wax deposit is formed.

The pressure-drop in CPIP model is shown as the comparison in a dash line.

in Figure 14. The decrease in the flow rate of oil in CPIP occurs drastically near the inlet and drops to $0.2 \%$ at the outlet compared with the inlet. Additionally, the flow rate of water at the outlet drops to $20 \%$ of the flow rate at the inlet. This decrease in the flow rates of oil and water indicates that the mass balance is significantly violated!

Furthermore, this decrease in flow rate in the CPIP model has a severe impact on the wax deposition by underestimating the liquid wax concentration. Figure 15 shows the comparison of the profiles of the bulk concentration of the CPIP and VPIP models initially $(t=0)$ when no wax deposit is formed. It is seen that for the VPIP model, the bulk concentration of wax slightly decreases along the channel due to the deposition of wax on the upper wall. For CPIP, however, a drastic underestimate of the soluble wax in the oil phase is seen as result of the decreasing oil flow rate along the channel calculated using this approach. This under-estimate reaches about $60 \%$ at the outlet. This difference in soluble wax in the oil phase indicates that the approach of CPIP greatly under-estimates the amount of soluble wax available for deposition.

Consequently, the CPIP model significantly under-predicts the growth rate of wax deposition. Figure 16 shows the oil/ deposit interface using both the CPIP and VPIP models after 700 days. It is seen that the approach of CPIP predicts a deposit maximum that reaches only $10 \%$ of the channel,

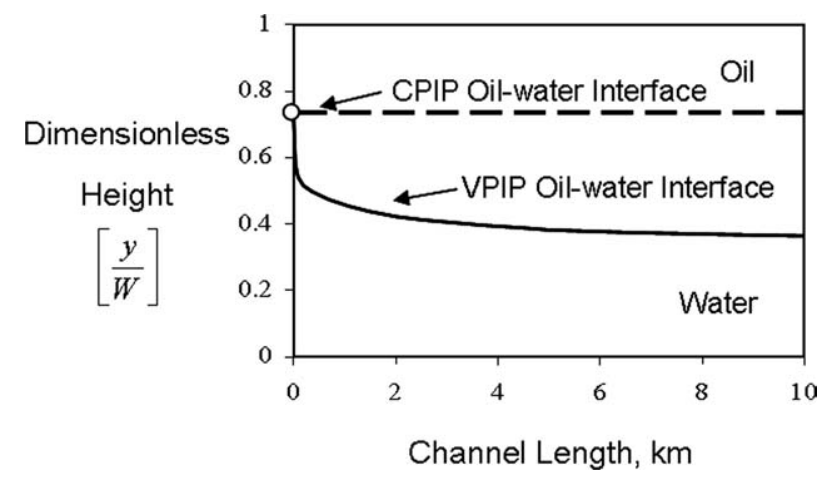

Figure 13. The change in oil/water interface position throughout the channel in VPIP initially ( $t=$ 0) when no wax deposit is formed.

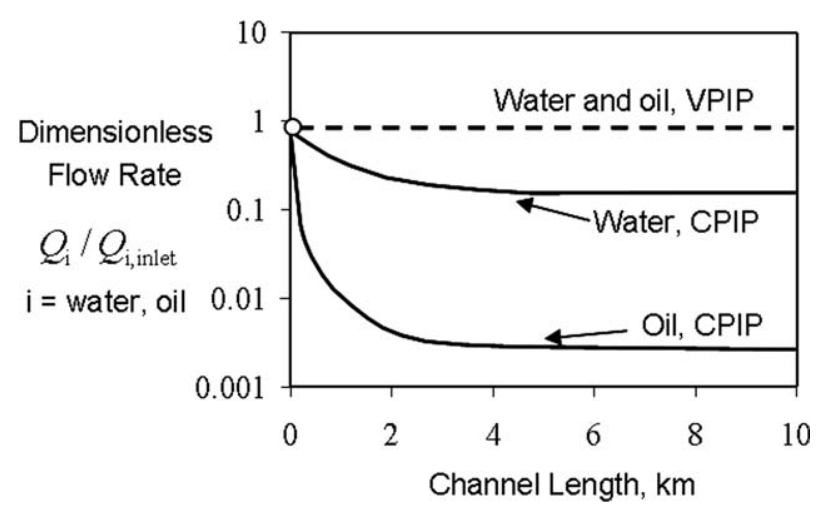

Figure 14. The decrease in the flow rates of oil and water throughout the channel in CPIP initially $(t=0)$ when no wax deposit is formed.

whereas, for the VPIP model, the deposit maximum occupies more than half of the channel.

The Prediction of Wax Deposition for Nonisothermal Oill Water Stratified Flow. We now investigate the effect of the ratio of water to oil flow rates on wax deposition. Incorporating the change of the pressure-drop and of the oil/water interface position in the calculations, the profiles of wax deposit for various water flow rates (Simulations 4-6 in Table 2) are shown in Figures 17-20. We first investigate the case where the water volumetric flow rate is $1 / 2$ of that of the oil. We see that the channel is virtually blocked after 480 days compared with 180 days of single-phase oil flow.

It is found that increasing the water flow rate significantly reduces the severity of wax deposition in stratified flow. First, a significant shift in the location of the deposit toward the outlet is seen when water is added. Additionally, the difference in the blockage times among Figures 10b, 17b, 18b, $19 \mathrm{~b}$, and $20 \mathrm{~b}$ denotes that the growth rate of deposit is significantly reduced as the amount of water increases. Figure 21 shows the time for the maximum of the deposit to block $95 \%$ of the channel as a function of the flow rate ratio of water to oil. It is seen that as the water fraction increases, the time to reach $95 \%$ blockage increases by as much as $300 \%$. Similar trends that water reduces the severity of wax deposition were also found by Singh et al. for vertical waterin-oil dispersed flows. ${ }^{22}$ The effects of water flow rate on

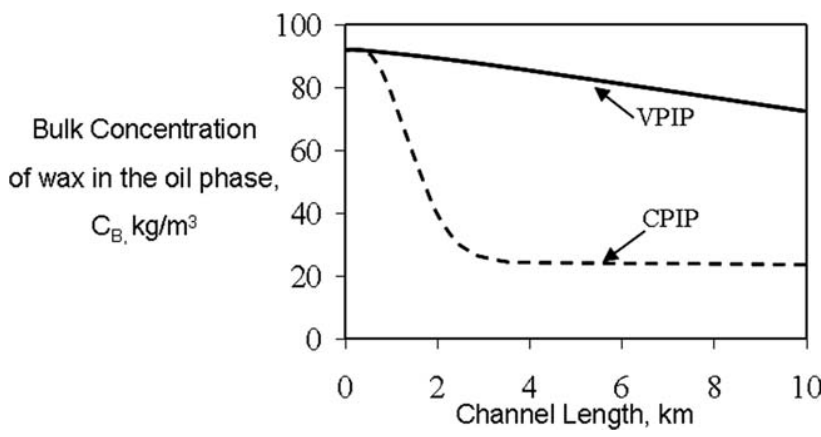

Figure 15. Bulk concentration of soluble wax in oil for CPIP and VPIP initially $(t=0)$ when no wax deposit is formed.

April 2011 Vol. 57, No. 4

AIChE Journal 

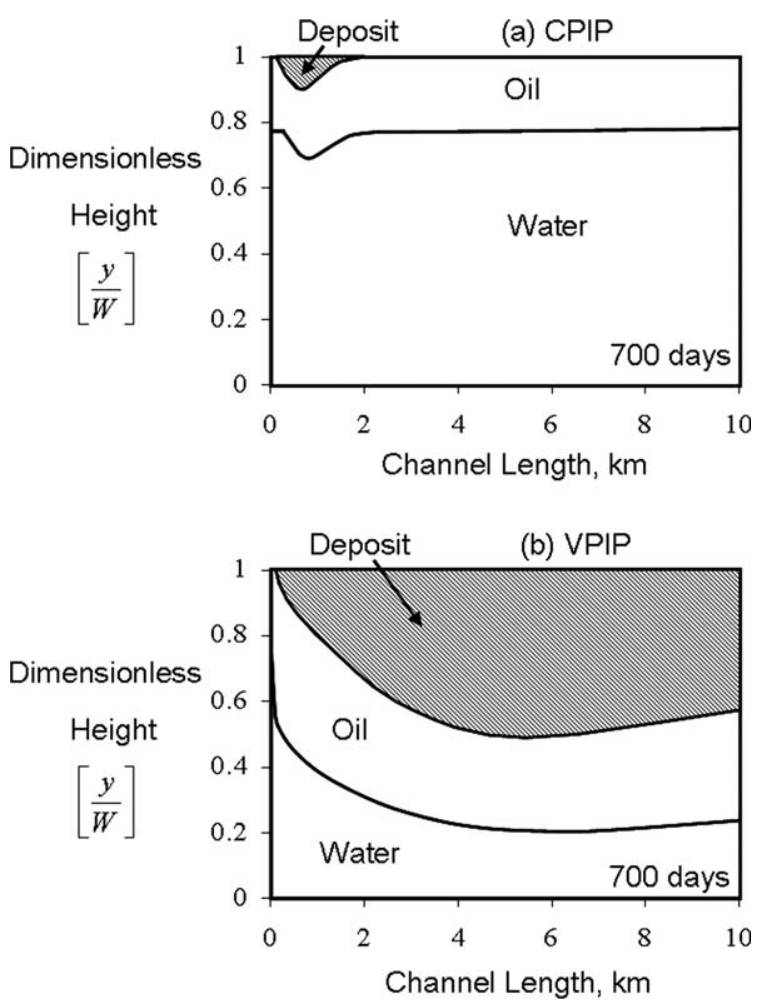

Figure 16. Deposition profile throughout the channel for CPIP (a) and VPIP (b) after 700 days.
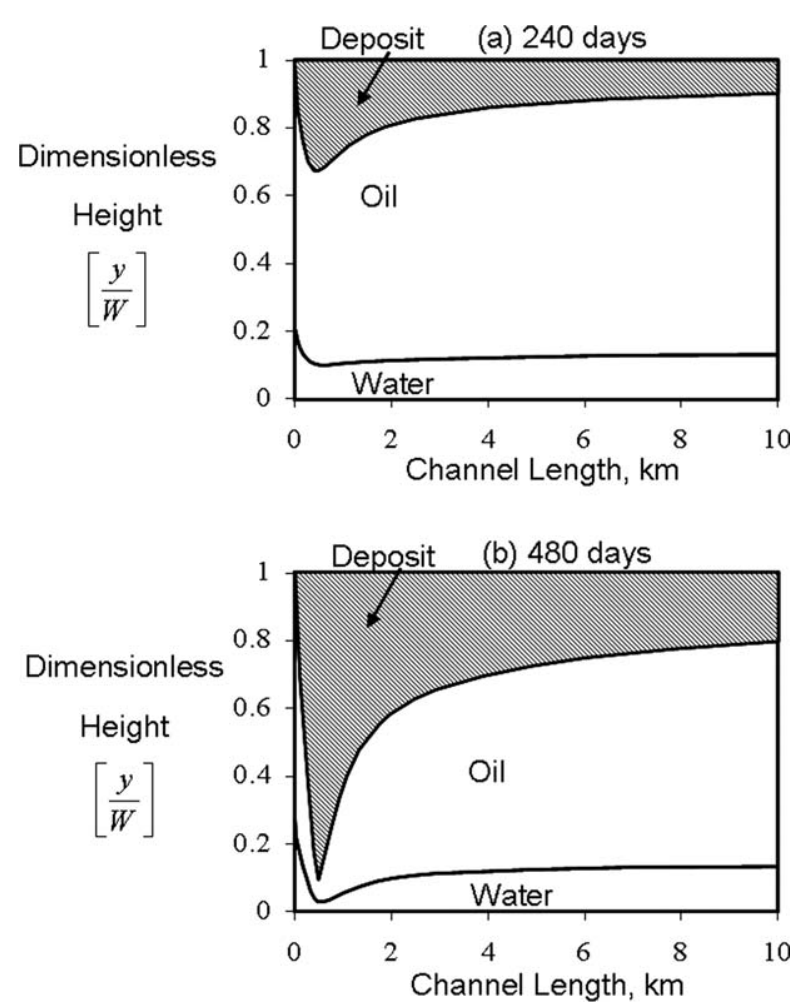

Figure 17. The growth of the deposit thickness for $Q_{w} /$ $Q_{0}=0.5$ (Simulation 4).
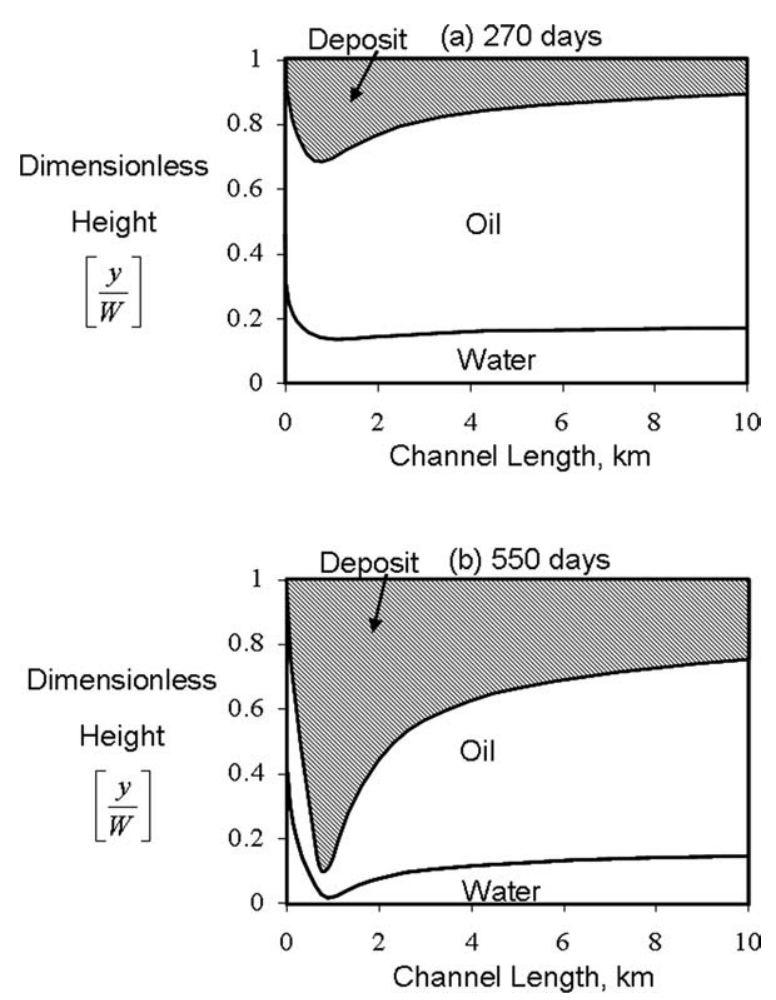

Figure 18. The growth of the deposit thickness for $\boldsymbol{Q}_{\mathrm{w}} /$ $Q_{0}=1$ (Simulation 5).
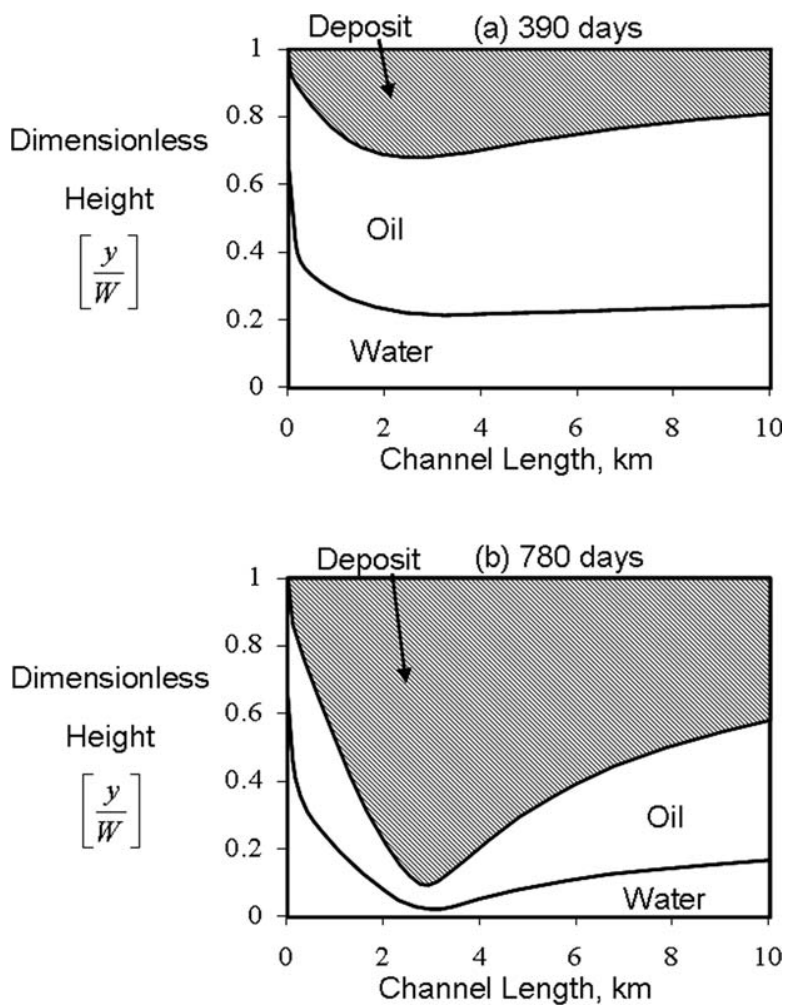

Figure 19. The growth of the deposit thickness for $Q_{w} /$ $Q_{0}=4$ (Simulation 6). 
wax deposition can be explained by the alternation in the heat and mass transfer characteristics in stratified flow conditions, as discussed in the next section.

Effect of the Presence of Water on Heat and Mass Transfer. In oil/water stratified flow, the oil phase is in contact with only the upper wall. Therefore, the water phase serves as an insulation barrier for mass transfer and prevents deposition on the lower wall. This physical impediment explains the jump shown in the curve in Figure 21 where water is present.

The presence of water has two major effects on the heat transfer and hence on wax deposition. Most importantly, the energy input to the system increases with increasing water fraction and flow rate. In this case, water serves as an energy source for the oil and retards cooling. Because water has a heat capacity that is generally twice of that of oil, water provides a significant amount of energy to the oil. On the other hand, the water phase acts as an insulating material to provide a thermal resistance for heat transfer to the lower wall and reduces the heat loss from the oil phase. When comparing the thermal conductivity of water $(0.6 \mathrm{~W} / \mathrm{m} / \mathrm{K})$ to polypropylene that is frequently used as insulation in offshore pipelines $(0.22 \mathrm{~W} / \mathrm{m} / \mathrm{K})$, the insulation of water is equivalent to polypropylene of about $1 / 3$ of its height in the stratified flow. These two effects of the presence of water lead to a gradual loss of energy of oil along the channel. Therefore, fewer wax molecule precipitate at the interface for deposition, leading to a decrease in the deposit growth rate and eventually a smaller deposit.
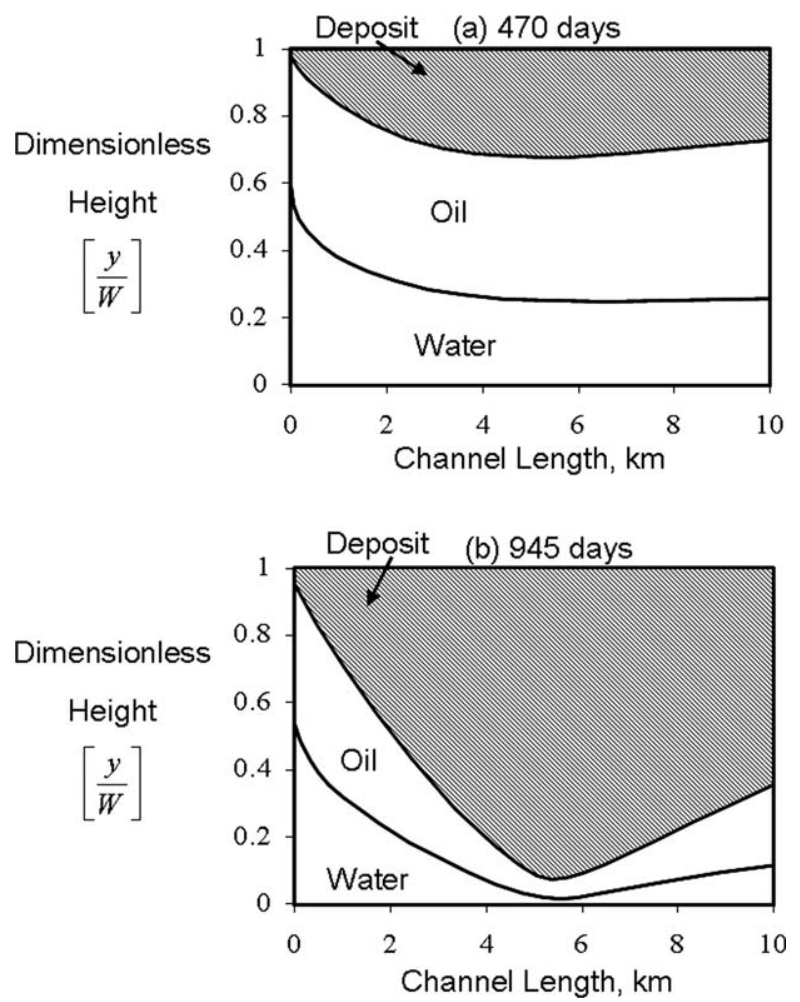

Figure 20. The growth of the deposit thickness for $Q_{w} /$ $Q_{0}=8$ (Simulation 3).

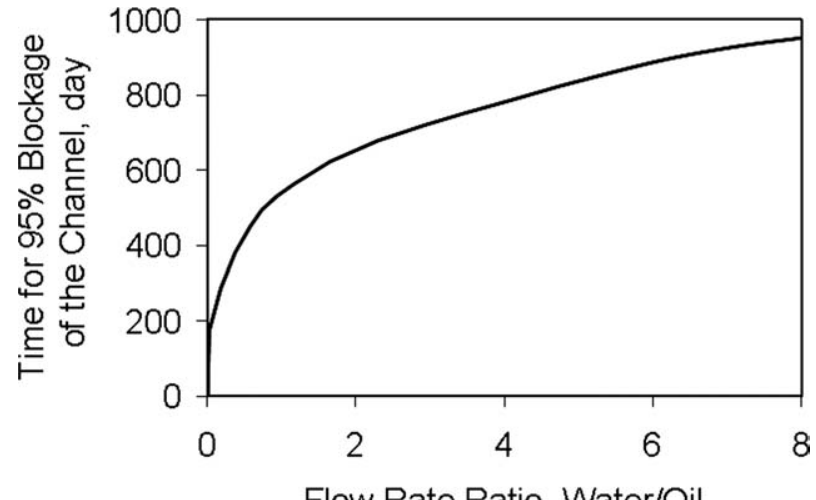

Figure 21. Comparison of predictive times for $95 \%$ blockage of the channel for different oil/ water flow rate ratios.

\section{Conclusions}

Pipe-flow hydrodynamics and heat/mass transfer need to be fundamentally studied using first principles to predict wax deposition. Correlations for heat/mass transfer in single-phase wax deposition modeling fail to give reliable predictions for multiphase flow systems, which introduced enormous complexity in transport phenomena because of the various possible flow patterns. Wax deposition modeling needs to be studied at each flow pattern to generalize applicable predictions.

In this work, wax deposition under nonisothermal oil/ water stratified flow conditions is studied. A unidirectionalflow assumption is used in the solution to nonisothermal hydrodynamics. The gradual decrease of fluid temperature during the flow results in a slow change in hydrodynamics along the pipe. Therefore, the unidirectional-flow approximation is reasonable in subsea pipeline conditions and prevents the need to iterate on the momentum balance equation, making it feasible for the prediction of wax deposition in field scale multiphase flow. A $2 \mathrm{D}$ model of oil/water flow between two parallel plates where deposition occurs at the upper wall has been developed. The simplification of unidirectional-flow in calculating the hydrodynamics of the subsea pipelines greatly reduce the computational intensity for field scale deposition modeling.

For nonisothermal flow conditions, it was found that the hydrodynamics down the channel changes significantly. This change occurs because the change in the bulk temperature of both phases causes the changes in the viscosities of oil and water as well as the ratio of these two values. The isothermal assumption of a constant pressure-drop and constant interface position cannot be used in this analysis because it violates the mass balance on the oil and water. In addition, it significantly under-predicts the growth rate and the amount of the wax deposit.

The nonisothermal hydrodynamics and the heat/mass transfer for stratified flow is studied to predict the growth of the wax deposit as a function of time. The deposit thickness increases along the channel near the inlet due to precipitation at the wall. As the bulk concentration of wax in the oil phase decreases, the driving force for deposition decreases, which leads to a decrease in deposit thickness near the outlet. 
The presence of water was found to significantly decrease the severity of wax deposition by changing the heat and mass transfer characteristics. This decrease can be seen in the location of the maximum of the deposit, which is much further from the inlet. In addition, when water is present, there is a longer time to reach the point of blockage of the channel. This increase in the time to blockage can be as much as $300 \%$.

From the point of mass transfer, the water phase will occupy a certain contact area to the wall thereby reducing the area of wall available for wax deposition. From the point of heat transfer, the presence of water provides additional energy to the system, which decreases the cooling rate of the oil in the channel. Furthermore, the water phase serves as an additional thermal resistance to the radial heat transfer, which reduces the heat loss to the surroundings and decreases the growth rate of the wax deposit.

\section{Acknowledgments}

The authors acknowledge financial support from the following members of the University of Michigan Joint Industry Program: Chevron Corporation, ConocoPhillips Company, Multiphase Solutions Inc., Nalco Company, Shell Global Solutions, Schlumberger Limited, Statoil ASA, and Total S. A.

\section{Notation}

\section{Hydrodynamics}

$H_{\text {water }}, H_{\text {oil }}=$ phase height of water/oil, m

$Q_{\text {water }}, Q_{\text {oil }}=$ flow rate of water/oil per unit depth of the channel, $\mathrm{m}^{2} / \mathrm{s}$

$R e_{\mathrm{w}}, R e_{\mathrm{o}}=$ Reynolds number of oil/water

$V_{\mathrm{x}}=$ velocity, $\mathrm{m} / \mathrm{s}$

$W=$ channel width, $\mathrm{m}$

$\mu_{\text {water }}, \mu_{\text {oil }}=$ viscosity of water/oil, $\mathrm{Pa} \cdot \mathrm{s}$

$\rho_{\text {water }}, \rho_{\text {oil }}=$ density of water/oil, $\mathrm{Pa} \cdot \mathrm{s}$

$\delta=$ deposit thickness, $\mathrm{m}$

$t=$ time, $\mathrm{s}$

\section{Heat/mass transfer}

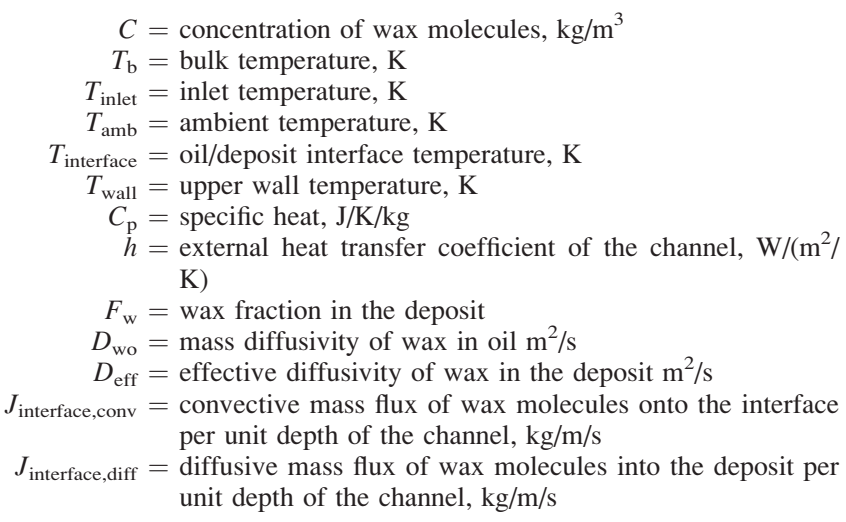

\section{Literature Cited}

1. Lee HS. Computational and Rheological Study of Wax Deposition and Gelation in Subsea Pipelines. PhD Thesis, University of Michigan, Ann Arbor, MI, 2007.

2. Bern PA, Withers VR, Cairns JR. Wax deposition in crude oil pipelines, In: Proceedings of European Offshore Petroleum Conference and Exhibition, London, 1980:571-578.

3. Burger ED, Perkins TK, Striegler JH. Studies of wax deposition in the trans-Alaska pipeline. J Petrol Technol. 1981;33:1075-1086.

4. Majeed A, Bringedal B, Overa S. Model calculates wax deposition for N. Sea Oils. Oil Gas J. 1990;88:63-69.

5. Hamouda, AA, Davidsen S. An approach for simulation of paraffin deposition in pipelines as a function of flow characteristics with a reference to Teesside oil pipeline. In: Proceedings of International Symposium on Oilfield Chemistry, Houston, 1995:459-470.

6. Brown, TS, Niesen VG, Erickson DD. Measurement and prediction of the kinetics of paraffin deposition. In: Proceedings of SPE Technical Conference and Exhibition, Houston, 1993:353-368.

7. Ribeiro FS, Souza M, Paulo R, Braga SL. Obstruction of pipelines due to paraffin deposition during the flow of crude oils. Int J Heat Mass Transfer. 1997;40:4319-4328.

8. Asperger A, Engewald W, Fabian G. Analytical characterization of natural waxes employing pyrolysis-gas chromatography-mass spectrometry. J Anal Appl Pyrolysis. 1999;52:103-115.

9. Singh P, Fogler HS. Formation and aging of incipient thin film waxoil gels. AIChE J. 2000;46:1059-1074.

10. Venkatesan R. The Deposition and Rheology of Organic Gels. PhD Thesis, University of Michigan, Ann Arbor, MI, 2004.

11. Barnea D, Brauner N. Holdup of the liquid slug in two phase intermittent flow. Int J Multiphas Flow. 1985;11:43-49.

12. Yu HS, Sparrow EM. Stratified laminar flow in ducts of arbitrary shape. AIChE J. 1967;13:10-16.

13. Shi H, Cai J, Jepson WP. Oil-water two-phase flows in large diameter pipelines. J Energy Resour Technol. 2001;123:270-276.

14. Matzain A, Apte MS, Zhang HQ, Volk M, Brill JP, Creek JL. Investigation of paraffin deposition during multiphase flow in pipelines and wellbores-part 1: experiments. J Energy Resour Technol Trans ASME. 2002;124:180-186.

15. Kim D, Ghajar AJ, Dougherty RL, Ryali VK. Comparison of 20 two-phase heat transfer correlations with seven sets of experiment data, including flow pattern and tube inclination effects. Heat Transfer Eng. 1999;20:15-40.

16. $\mathrm{Ng}$ TS, Lawrence CJ, Hewitt GF. Laminar stratified pipe flow. Int J Multiphas Flow. 2002;28:963-996.

17. Gemmell AR, Epstein N. Numerical analysis of stratified flow of two immiscible Newtonian fluids in a circular pipe. Can J Chem Eng. 1962;40:215-224.

18. Deen WM. Analysis of Transport Phenomena. New York, Oxford: Oxford University Press, 1998.

19. Tanehill JC, Anderson DA, Pletcher RH. Computational Fluid Mechanics and Heat Transfer. Philadelphia, PA: Taylor and Francis, 1997.

20. Hayduk W, Minhas BS. Correlations for prediction molecular diffusivities in liquids. Can J Chem Eng. 1982;60:295-299.

21. Cussler EL, Hughes SE, Ward WJ, Aris R. Barrier membranes. $J$ Membr Sci. 1988;38:161-174.

22. Singh PJ, Walker A, Lee HS, Gharfeh SG, Thomason W, Blumer D. An application of vacuum-insulated tubing (VIT) for wax control in an arctic environment. SPE Drilling Completion. 2007;22:127-136.

Manuscript received Dec. 10, 2009, revision received Mar. 19, 2010, and final revision received May $18,2010$. 